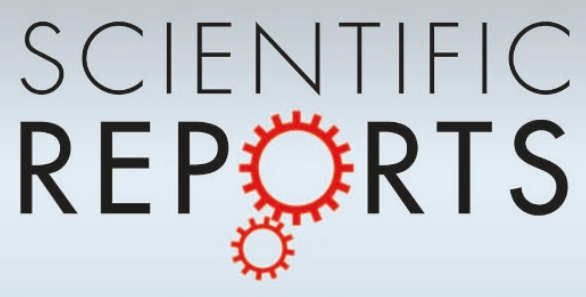

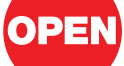

SUBJECT AREAS:

BEHAVIOURAL ECOLOGY

HERPETOLOGY

TROPICAL ECOLOGY

ECOLOGICAL EPIDEMIOLOGY

Received

13 December 2012

Accepted

6 March 2013

Published

21 March 2013

Correspondence and requests for materials should be addressed to J.J.L.R. (jodi.rowley@ austmus.gov.au)

\section{Hot bodies protect amphibians against chytrid infection in nature}

\author{
Jodi J. L. Rowley ${ }^{1,2} \&$ Ross A. Alford'
}

'School of Marine and Tropical Biology and Amphibian Disease Ecology Group, James Cook University, Townsville, QLD 4811 ,
Australia, ${ }^{2}$ Australian Museum, 6 College St, Sydney, NSW 2010, Australia.

Environmental context strongly affects many host-pathogen interactions, but the underlying causes of these effects at the individual level are usually poorly understood. The amphibian chytrid fungus has caused amphibian population declines and extinctions in many parts of the world. Many amphibian species that have declined or have been extirpated by the pathogen in some environments coexist with it in others. Here we show that in three species of rainforest frogs in nature, individuals' probability of infection by the amphibian chytrid fungus was strongly related to their thermal history. Individuals' probability of infection declined rapidly as they spent more time above the pathogen's upper optimum temperature. This relationship can explain population-level patterns of prevalence in nature, and suggests that natural or artificial selection for higher thermal preferences could reduce susceptibility to this pathogen. Similar individual-level insights could improve our understanding of environmental context-dependence in other diseases.

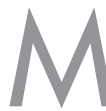
any symbiotic relationships can be modified extensively by environmental conditions ${ }^{1}$. Harmless symbiotes can become pathogenic, and mutualistic relationships can break down ${ }^{1}$. The emerging infectious disease chytridiomycosis, caused by the amphibian chytrid fungus Batrachochytrium dendrobatidis $(B d)$, is an excellent system for examining such environmental context dependence. Chytridiomycosis has caused amphibian population declines and extinctions in many parts of the world ${ }^{1,2}$, yet many amphibian species that have declined or have been extirpated by the disease in some environments coexist with $B d$ in others ${ }^{1-4}$. Additionally, some infected amphibians can survive for years in the wild with no clinical signs of disease $e^{5}$, and some species that coexist with endemic chytridiomycosis in the field can be highly susceptible to $B d$ in the laboratory, experiencing $100 \%$ mortality ${ }^{6}$.

It is known that environmental temperature can determine the progress and outcome of $B d$ infections in the laboratory. In culture, $B d$ grows best between 17 and $25^{\circ} \mathrm{C}^{7}$. In the laboratory, low and/or fluctuating temperatures can retard the pathogen's growth, and elevated body temperatures can clear frogs of $B d$ infection ${ }^{6}$. In nature, population-level infection prevalence and host mortality rates are often correlated with ambient environmental conditions; the infection rates are highest during cooler months ${ }^{2-4}$ and at higher elevations ${ }^{4}$. Similar contextdependence occurs in other host-pathogen systems ${ }^{1}$.

One study ${ }^{8}$ has shown that after the first appearance of chytridiomycosis in a susceptible population, mean body temperatures of frogs increased, which should reduce the negative effects of the pathogen. Increases in mean body temperature at the population level could reflect adaptive responses of individuals to infection, shifting thermal preferences to produce "behavioural fever". However it could also result from selective sweeps in which individuals that attain higher temperatures for other reasons ${ }^{9}$ are more likely to survive during outbreaks of chytridiomycosis. Understanding such population-level responses and determining their implications for the management of amphibian populations requires information on the individual-level patterns that underlie the population-level relationships.

In order to examine the relationship between $B d$ infection status and individual thermal behavior, we measured the $B d$ infection status and body temperatures in nature of stream-associated rainforest frogs of three species that have declined to different degrees due to chytridiomycosis in rainforests of northern Queensland, Australia; Litoria lesueuri (least affected by declines), Litoria serrata (intermediate) and Litoria nannotis (most affected). Frogs were tracked in the summer/wet and winter/dry seasons at a total of four rainforest sites and their individual body temperatures were recorded nocturnally and diurnally every $24 \mathrm{~h}$.

\section{Results}

Infection prevalence did not differ significantly among sites within seasons for any of the three species (Fisher's exact tests, all $\mathrm{P}>0.05$ ). Infection prevalence appeared to differ among species and seasons (Fig. 1a). Our 

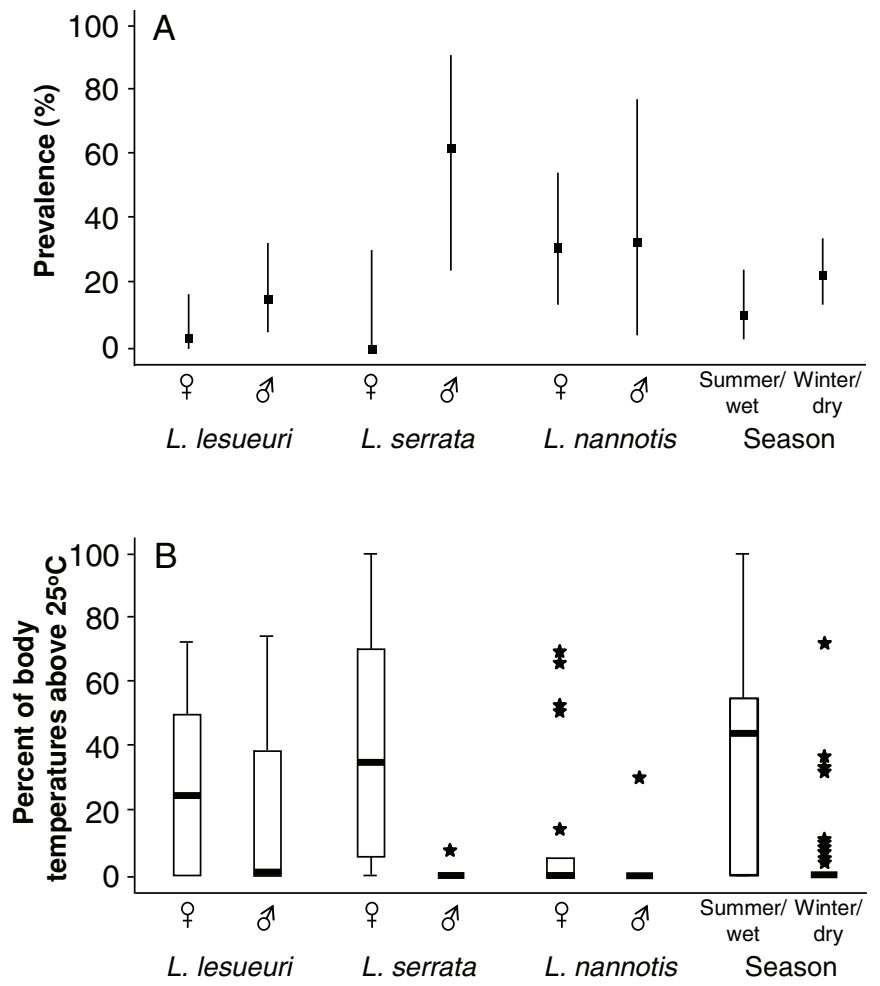

Figure 1 Individual probability of infection by the amphibian chytrid skin fungus and individual thermal history in nature. (a) Prevalence of $B d$ infection in tracked frogs by species and gender and by season. Bars represent binomial (Clopper-Pearson) 95\% confidence limits.

(b) Boxplots illustrating distribution of percent of frog body temperatures above $25^{\circ} \mathrm{C}$ by species and gender and by season. Heavy bars represent medians, boxes represent $25 \%$ and $75 \%$ quartile boundaries, whiskers represent ranges, and stars are points outside $1.5 \times$ the interquartile range from the nearest quartile boundary. Comparing (a) and (b) suggests an inverse relationship between prevalence and percent of body temperatures above $25^{\circ} \mathrm{C}$; this relationship was explored statistically in the models presented in Table 2 .

ANOVA showed that the proportions of individuals' body temperatures that were above $25^{\circ} \mathrm{C}$ (this temperature was chosen as the cutoff because in vitro the growth rate of $B d$ declines sharply above that temperature ${ }^{7}$ ) was significantly affected by species, gender, season, and their interactions (Table 1; Fig. 1b).

Model fitting and selection of models relating species, gender, season, and proportion of individual body temperatures above $25^{\circ} \mathrm{C}$ produced three candidate models with delta AICc less than 3 (Table 2). These were averaged to produce a final model that included the effects of species, gender, and proportion of body temperatures above $25^{\circ} \mathrm{C}$ (Table 2; Fig. 2). The averaged model shows that individual probabilities of infection by $B d$ decreased strongly with increasing percentage of body temperatures above $25^{\circ} \mathrm{C}$ in all

Table $1 \mid$ Analysis of variance for the effects of species, gender (sex) and season (cold, dry or warm, wet, season) on individual thermal history, measured as proportion of individual body temperatures that were above $25^{\circ} \mathrm{C}$

\begin{tabular}{lrrrrr} 
Effect & SS & df & MS & \multicolumn{1}{c}{$F$} & \multicolumn{1}{c}{$P$} \\
\hline Species & 0.740 & 2 & 0.370 & 41.262 & $<0.001$ \\
Sex & 0.125 & 1 & 0.125 & 4.461 & 0.037 \\
Season & 3.962 & 1 & 3.962 & 141.107 & $<0.001$ \\
Error & 2.920 & 97 & 0.028 & & \\
\hline
\end{tabular}

Table 2 | Logistic regression models evaluated as possible fits to infection status ( $0=$ infected, $1=$ uninfected) of tracked frogs. All possible one, two, and three-variable main-effects only models involving species identity (Species), gender of the individual (Sex), season (summer/wet season or winter/dry season, Season), and the proportion of body temperatures measured for each individual that were greater than $25^{\circ} \mathrm{C}$ (PA25) were considered. Models including more than three main effects or interactions were not included to preclude overfitting. The three best fitting models, with a total Akaike weight of 0.705 , were averaged to obtain the final model. Predictions of this model appear in Figure 2

Initial models

\begin{tabular}{lrccc}
\hline Effects in model & AICc & Delta AICc & $\begin{array}{c}\text { Akaike } \\
\text { weight }\end{array}$ & $\begin{array}{c}\text { Nagelkerke } \\
\mathrm{R}^{2}\end{array}$ \\
\hline Sex, Species, PA25 & 94.930 & 0.000 & 0.398 & 0.264 \\
Species, PA25 & 96.507 & 1.577 & 0.181 & 0.215 \\
Sex, Species & 97.237 & 2.307 & 0.126 & 0.206 \\
Species, Sex, Season & 98.098 & 3.168 & 0.082 & 0.223 \\
Season, Species, PA25 & 98.632 & 3.702 & 0.063 & 0.216 \\
PA25 & 99.366 & 4.436 & 0.043 & 0.119 \\
Sex, PA25 & 99.683 & 4.753 & 0.037 & 0.144 \\
Sex, Season, PA25 & 101.057 & 6.127 & 0.019 & 0.155 \\
Season, PA25 & 101.150 & 6.220 & 0.018 & 0.124 \\
Species, Season & 101.459 & 6.529 & 0.015 & 0.149 \\
Species & 102.090 & 7.160 & 0.011 & 0.111 \\
Sex & 104.602 & 9.672 & 0.003 & 0.045 \\
Sex, Season & 104.794 & 9.864 & 0.003 & 0.072 \\
Season & 104.944 & 10.014 & 0.003 & 0.040 \\
\hline
\end{tabular}

Final averaged model

\begin{tabular}{lclc}
\hline Effect & $\beta$ & S.E. & $P$ \\
\hline Intercept & -0.157 & 0.690 & 0.585 \\
Species: lesueuri & 1.737 & 0.721 & 0.014 \\
Species: serrata & 0.228 & 0.820 & 0.781 \\
Species: nannotis & $0 *$ & $0 *$ & - \\
Sex: Female & 1.264 & 0.642 & 0.049 \\
Sex: Male & $0 *$ & $0 *$ & - \\
PA25 & 3.376 & 1.838 & $0.033^{+}$ \\
\hline
\end{tabular}

"coefficients structurally set to zero; ${ }^{\circ}$ one-tailed $\mathrm{P}$ value due to pre-existing hypothesis regarding effect direction (higher PA25 should decrease P(infection)).

three species (Fig. 2). Males and females of the least vulnerable species (L. lesueuri) had the lowest probabilities of infection. Females of the two more vulnerable species had moderate probabilities of infection, particularly if they rarely elevated their body temperatures above $25^{\circ} \mathrm{C}$, and males of those species had the highest probabilities of infection. Frogs of all species and genders were very unlikely to carry $B d$ infections if $75 \%$ or more of their body temperatures were above $25^{\circ} \mathrm{C}$. No separate effects of season appeared in our best fitting models, suggesting that seasonal differences in infection prevalence are explained by effects of season on individual body temperatures.

\section{Discussion}

Our study is the first demonstration that individual thermal histories affect the probability of infection by $B d$ of frogs in nature, and one of the first examining how individuals' environmental histories affect their vulnerability to disease in wildlife. We found that individual probabilities of infection by $B d$ decreased strongly with increasing percentage of body temperatures above $25^{\circ} \mathrm{C}$ in all three species of rainforest stream frog examined. This relationship can explain population-level patterns of prevalence in nature ${ }^{2-4}$.

The effects of species and gender on individual probabilities of infection by $B d$ probably reflect a combination of differences in 


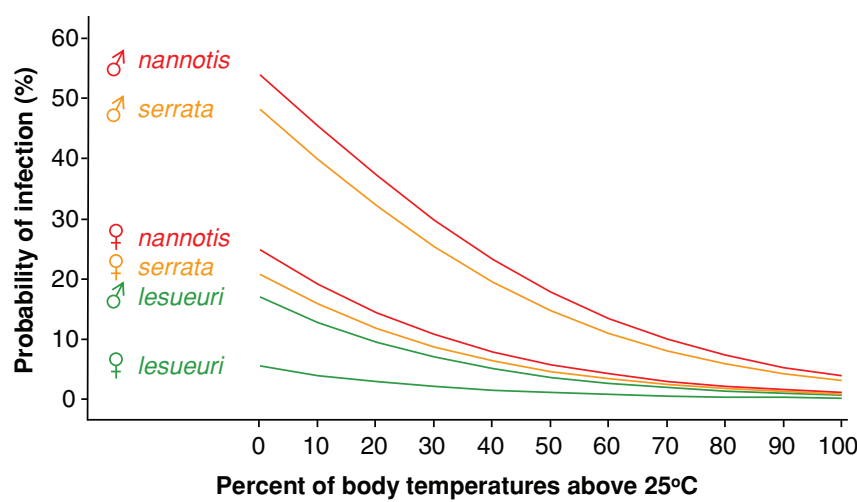

Figure 2 Individual probability of infection by the amphibian chytrid skin fungus in nature was strongly related to individual thermal history. This logistic model, incorporating species identity, gender, and percent of body temperatures above $25^{\circ} \mathrm{C}$ (Table 2 ), was produced by averaging the three best fitted models, each with delta AICC $<3$. Color coding corresponds to species-level susceptibility to epidemic chytridiomycosis (red most, amber intermediate, green least). Predictions of the model correspond well ( $\mathrm{r}^{2}=0.739,4$ d.f., $\left.\mathrm{P}=0.028\right)$ with population-level patterns of prevalence when it is used to predict prevalence by season and site, factors not included in the model.

immune function and differences in transmission rates $^{2,10}$. Our measure of thermal history, the percentage of individual body temperatures above $25^{\circ} \mathrm{C}$, is directly related to the known thermal sensitivity of $B d$ in vitro; it thus seems likely that the effects we found were caused by direct effects on rates of pathogen reproduction ${ }^{2,6,7}$, however they could also reflect responses of frogs' immune function to temperature ${ }^{11}$.

Our findings are not highly consistent with the hypothesis that frogs elevated their body temperatures in response to infection (behavioural fever $)^{8}$, since the probability of infection declined dramatically with increasing time spent at higher body temperatures. However, we cannot entirely eliminate the possibility that infection may cause individuals to regulate their body temperatures at higher levels than normal. For example, if thermal preferenda vary among individuals, we may have only seen infections in those that normally have low upper set points and in whom raising the set point has failed to elevate temperatures sufficiently to reduce their probability of infection. Alternatively, infection could lead to long-term changes in thermoregulatory behaviour, so that a propensity to maintain a relatively high body temperature reflects what might be termed the ghost of infection past.

Our results may also have a simpler cause. Individuals that choose relatively high body temperatures for other reasons, i.e. to aid in growth, digestion ${ }^{9}$, or reproduction ${ }^{3}$ may have coincidentally decreased their probability of $B d$ infection. While $B d$ remains endemic, any tendency to maintain higher body temperatures could be reinforced by natural selection. Alternatively, our results could reflect a tendency for infected individuals to maintain relatively low body temperatures. This could be coincidental; e.g. lower activity levels in infected individuals could have reduced their opportunities for thermoregulation. It could also reflect manipulation of hosts by the pathogen. These hypotheses regarding cause and effect can only be resolved by future experimental work.

Regardless of the cause, our results show that individual histories of body temperature can explain a substantial fraction of the seasonal, elevational, and interspecific patterns of $B d$ infection prevalence that have been observed in nature ${ }^{1-4}$. Variation in thermal preferences among individuals should provide opportunities for natural selection to reduce vulnerability to chytridiomycosis. Manipulating habitats to increase the availability of warmer temperatures may serve as a mechanism to increase the survival of threatened amphibians in nature. The effects of global change are likely to vary among species and sites; for example increased temperatures might tend to decrease the effects of $B d$, but increases in cloud or canopy cover could tend to increase them. Our results highlight the importance of the effects of body temperature variation among and within individuals on host-pathogen systems involving ectothermic animals.

\section{Methods}

Study sites. The study was conducted at four streamside sites within the tropical rainforests of northern Queensland, Australia: Python Creek ("Tully Gorge", $145^{\circ} 35^{\prime} \mathrm{E} 17^{\circ} 46^{\prime} \mathrm{S}, 200 \mathrm{~m}$ asl) and an unnamed creek ("Lower Tully", $145^{\circ} 41^{\prime} \mathrm{E}$ $17^{\circ} 48^{\prime} \mathrm{S}$; $70 \mathrm{~m}$ asl) in Tully Falls Forest Reserve, an unnamed creek in Kirrama State Forest ("Kirrama", $145^{\circ} 52$ E $18^{\circ} 11 \mathrm{~S} ; 200 \mathrm{~m}$ asl), and Frenchman Creek, in Wooroonooran National Park (“Babinda”, 1455' E 17²0' S 20-100 m asl). A marked transect at each stream served as a reference for frog locations.

Study species. Frogs of three species were tracked: the Stony Creek Frog L. lesueuri (31 females, 37 males), which has not experienced population declines ${ }^{12}$, the Green Eyed Treefrog L. serrata (10 females, 13 males), which declined during epidemics of chytridiomycosis in the late 1980s and early 1990s and subsequently recovered ${ }^{12}$, and the Waterfall Frog L. nannotis (29 females, 8 males), which was extirpated from many sites during chytridiomycosis epidemics ${ }^{12}$. The taxonomy of $L$. lesueuri was revised in $2004^{13}$. Two newly recognized species, L. jungguy and L. wilcoxii, occur in sympatry in the study region, hybridise, and cannot reliably be distinguished morphologically ${ }^{13}$. Our study populations could have included either species, mixtures of both, and hybrid individuals. Population declines have not been observed in either species. We therefore continue to refer to the study species as L. lesueuri, while recognizing that our samples contain unknown proportions of the two morphologically indistinguishable species. All three species are large to medium sized hylids (males 5.4-12.5 g, females 6.5-41.3 g).

Tracking. At initial capture, frogs were weighed and swabbed on the ventral surface for diagnostic PCR using a sterile rayon swab (Medical Wire \& Equipment Co. (Bath) Ltd., Wiltshire, UK). Swab samples were analysed using diagnostic PCR or quantitative $\mathrm{PCR}^{14}$.

Tracking devices (radio transmitters, or diode tags for harmonic direction finding, depending on size of the frog ${ }^{16}$ ) were then fitted in situ and frogs were released at their point of capture after less than five minutes of handling. Tracking followed protocols we have previously published ${ }^{15}$.

Surveys lasted 16 days and were conducted in the winter/dry season (July-September) and the summer/wet season (February-April) at two sites for each species. Litoria genimaculata and L. nannotis were tracked simultaneously at the same streams during 2004 and L. lesueuri were tracked during 2005. During surveys, the location of each frog was determined once during the day (0900-1800 h) and once at night (1900-0400 h). Whenever possible, the temperatures of located frogs and their substrates were recorded.

When we could visually locate individual frogs, and were able to reach within $0.5 \mathrm{~m}$ of them, temperature of the dorsal body surface was measured using a Raytek ST80 Pro-Plus Non-contact Thermometer (RAYST80, emissivity set to 0.95). This technique obtains body temperature readings within $0.5^{\circ} \mathrm{C}$ of cloacal temperatures ${ }^{17}$. When the infrared thermometer could not be used, if the frog was fitted with a temperature-sensitive transmitter, we recorded the pulse interval of the telemetry signal by timing 90 pulses with a stopwatch. This was converted to temperature using individual calibration curves for each transmitter.

On average, each frog was located 17 times (minimum 5, maximum 28). We excluded data from the night following tag attachment from analyses due to the potential short-term behavioural effects of handling ${ }^{18}$. Effects of tags on behavior are unlikely to persist after the first night of tag attachment ${ }^{16}$. The weights of tracked individuals did not change significantly over the study period (Wilcoxon Signed Ranks Test; $\mathrm{Z}=-1.361, p=0.173, \mathrm{n}=70$ ). Research was carried out under Scientific Purposes Permits issued by the Queensland Parks and Wildlife Service (WISP01715204 and WITK01715604) and approved by the James Cook University Animal Care and Ethics Committee (A863).

Data analyses. On swabs analysed using qPCR, we measured between 6 and 10,527 zoospore genome equivalents per swab. As $\sim 20 \%$ of our samples were analysed via PCR only, we included only infection prevalence in our statistical analyses. Because tracking did not occur at the same sites for all three species, we could not include site as a factor in orthogonal models. We initially examined our data for possible site-specific effects using Fisher's exact tests to determine whether infection prevalence differed significantly among sites within seasons for each species. It did not (Fisher's exact tests; all $p>0.05$ ). We thus omitted site as a factor in all further analyses. We next examined whether individual thermal history, measured as the proportion of body temperatures of each individual that were greater than $25^{\circ} \mathrm{C}$, was affected by species, gender, and season, using an ANOVA in SPSS version 19. This analysis showed that thermal histories were affected by all those factors. Finally, we examined how $B d$ infection status $(0=$ infected, $1=$ uninfected $)$ was affected by 
species, gender, season, and the thermal histories of individuals (proportion of body temperatures above $25^{\circ} \mathrm{C}$ ), using a set of models created using the generalized linear models procedure in SPSS version 19 with a binary logistic link function (Table 2). We used Akaike's information criterion, corrected for finite sample size (AICc) to evaluate model fit, using the criteria of Burnham and Anderson ${ }^{19}$. Our best fitting models were averaged to obtain the final model ${ }^{19}$.

1. Daskin, J. H. \& Alford, R. A. Context-dependent symbioses and their potential roles in wildlife diseases. Proc R. Soc. B 279, 1457-1465 (2012).

2. Alford, R. A. in Ecotoxicology of Amphibians and Reptiles (ed Sparling, D. W.) 13-46 (SETAC Press, 2010).

3. Puschendorf, R. et al. Environmental refuge from disease-driven amphibian extinction. Conserv. Biol. 25, 956-964 (2011).

4. Woodhams, D. C. \& Alford, R. A. The ecology of chytridiomycosis in rainforest stream frog assemblages of tropical Queensland. Conserv. Biol. 19, 1449-1459 (2005).

5. Retallick, R. W. R., McCallum, H. \& Speare, R. Endemic infection of the amphibian chytrid fungus in a frog community post-decline. PLoS ONE 2 (11), e351 (2004).

6. Woodhams, D. C., Alford, R. A. \& Marantelli, G. Emerging disease of amphibians cured by elevated body temperature. Dis. Aquat. Organ. 55, 65-67 (2003).

7. Piotrowski, J. S., Annis, S. L. \& Longcore, J. E. Physiology of Batrachochytrium dendrobatidis, a chytrid pathogen of amphibians. Mycologia 96, 9-15 (2004).

8. Richards-Zawacki, C. L. Thermoregulatory behaviour affects prevalence of chytrid fungal infection in a wild population of Panamanian golden frogs. Proc. $R$. Soc. B 277, 519-528 (2010).

9. Witters, L. R. \& Sievert, L. Feeding causes thermophily in the woodhouse's toad (Bufo woodhousii). J. Thermal Biol. 26, 205-208 (2001).

10. Rowley, J. J. L. \& Alford, R. A. Behaviour of Australian rain forest stream frogs may affect the transmission of chytridiomycosis. Dis. Aquat. Organ 77, 1-9 (2007)

11. Carey, C., Maniero, G. D. \& Stinn, J. F. in Adaptations to the Cold: Tenth International Hibernation Symposium (ed Geiser, F., Hulbert, A. J. \& Nicol, S. C.) 123-129 (University of New England Press, 1996).

12. McDonald, K. R. \& Alford, R. A. in Declines and Disappearances of Australian Frogs (ed Campbell, A.)14-22 (Environment Australia, 1999).

13. Donnellan, S. C. \& Mahony, M. J. Allozyme, chromosmal and morphological variability in the Litoria lesueuri species group (Anura: Hylidae), including a description of a new species. Aust. J. Zool. 52, 1-28 (2004).

14. Boyle, D., Boyle, D. B., Olsen, V., Morgan, J. A. T. \& Hyatt, A. D. Rapid quantitative detection of chytridiomycosis (Batrachochytrium dendrobatidis) in amphibian samples using real-time Taqman PCR assay. Dis. Aquat. Org. 60, 141-148 (2004).

15. Rowley, J. J. L. \& Alford, R. A. Movement patterns and habitat use of rainforest stream frogs in northern Queensland, Australia: implications for extinction vulnerability. Wildl. Res. 34, 371-378 (2007).

16. Rowley, J. J. L. \& Alford, R. A. Techniques for tracking amphibians: The effects of tag attachment, and harmonic direction finding versus radio telemetry. Amphibia Reptilia 28, 367-376 (2007).

17. Rowley, J. J. L. \& Alford, R. A. Non-contact infrared thermometers can accurately measure amphibian body temperatures. Herpetol. Rev. 38, 308-311 (2007).

18. Langkilde, T. \& Alford, R. A. The tail wags the frog: Harmonic radar transponders affect movement behavior in Litoria lesueuri. J. Herpet. 36, 711-715 (2002).

19. Burnham, K. P. \& Anderson, D. R. Model Selection and Multi-Model Inference: A Practical Information-Theoretic Approach (Springer-Verlag, 2002).

\section{Acknowledgements}

This research was supported by funding from the Australian Geographic Society, the Society for the Study of Amphibian and Reptiles, the Peter Rankin Trust Fund for

Herpetology, the Australian Department of Environment and Heritage (RFT 43-2004), and from US National Science Foundation Integrated Research Challenges in Environmental Biology grant DEB-0213851. J.J.L.R. was supported by an Australian Postgraduate Research Scholarship. Thanks to volunteers who assisted in the field, and to Stanwell Corporation Ltd. Ruth Campbell at the School of Veterinary and Biomedical Science, James Cook University, and Alex Hyatt at the Australian Animal Health Laboratory, CSIRO tested swabs for $B$. dendrobatidis.

\section{Author contributions}

J.J.L.R. and R.A.A. conceived this project. J.J.L.R. conducted field work, R.A.A. analysed the results and J.J.L.R. and R.A.A. wrote and edited the manuscript.

\section{Additional information}

Competing financial interests: The authors declare no competing financial interests.

License: This work is licensed under a Creative Commons

Attribution-NonCommercial-NoDerivs 3.0 Unported License. To view a copy of this license, visit http://creativecommons.org/licenses/by-nc-nd/3.0/

How to cite this article: Rowley, J.J.L. \& Alford, R.A. Hot bodies protect amphibians against chytrid infection in nature. Sci. Rep. 3, 1515; DOI:10.1038/srep01515 (2013). 